\title{
Management of Rare Histological Types of Breast Tumours
}

\author{
Toralf Reimer \\ Department of Obstetrics and Gynaecology, University of Rostock, Klinikum Suedstadt, Germany
}

Key Words

Breast tumour · Histology · Pathology · Prognosis ·

Treatment strategies

\section{Summary}

Breast tumours exhibit a wide range of morphological phenotypes, and specific histopathological types have particular prognostic and clinical characteristics. The management of uncommon premalignant and malignant lesions is often controversial due to the lack of large single-institution studies or randomised trials to define optimal treatments. In the era of frequent use of treatment guidelines, only a low level of evidence exists for the management of rare histological types of breast tumours. This review is divided into two parts: Firstly, the favourable histological subtypes like tubular, mucinous, medullary breast cancers, and phyllodes tumour (benign, borderline, and malignant) are discussed. The prognosis of these selected lesions is believed to be better than for invasive ductal carcinoma so that in some cases even less aggressive treatment should be considered. Patients with these specific histological types should be informed of this relatively favourable prognosis. Secondly, management recommendations for special situations like Paget's disease (tumour of the nipple) and inflammatory breast carcinoma are presented.

\section{Introduction}

The World Health Organization (WHO) classification of breast tumours distinguishes between benign and malignant

\author{
Schlüsselwörter \\ Brusttumor · Histologie - Pathologie · Prognose · \\ Behandlungsstrategien
}

\section{Zusammenfassung}

Brusttumoren umfassen ein breites Spektrum verschiedener morphologischer Phänotypen, und bestimmte histopathologische Typen besitzen besondere prognostische und klinische Charakteristika. Das Vorgehen bei ungewöhnlichen prämalignen und malignen Subtypen ist oft kontrovers, bedingt durch das Fehlen großer monozentrischer Studien bzw. randomisierter Studien als Grundlage optimaler Behandlungsstrategien. Im Zeitalter klinischer Leitlinien besteht ein niedriges „level of evidence" für das Vorgehen bei seltenen histologischen Formen. Diese Übersichtsarbeit ist in zwei Teile gegliedert: Zuerst werden histologische Subtypen mit einer günstigen Prognose wie das tubuläre, das muzinöse und das medulläre Mammakarzinom sowie der Phylloidtumor (benigne, Borderline und maligne) diskutiert. Die Prognose dieser ausgewählten Läsionen erscheint besser im Vergleich zum invasiv duktalen Mammakarzinom und sollte in bestimmten Fällen zu einer weniger aggressiven Therapie führen. Patientinnen, die an einer dieser Sonderformen erkrankt sind, sollten über die günstige Prognose aufgeklärt werden. Zweitens werden Behandlungsstrategien für den Morbus Paget der Brust (Sonderstellung als Tumor der Mamille) sowie für das inflammatorische Mammakarzinom vorgestellt.

tumours, and among these subgroups between epithelial and myoepithelial lesions, mesenchymal tumours, tumours of the nipple, malignant lymphomas, and metastatic tumours. Breast tumours exhibit a wide range of morphological phenotypes,

\begin{tabular}{ll}
\hline KARGER & @ 2008 S. Karger GmbH, Freiburg \\
Fax +49 7614520714 & Accessible online at: \\
$\begin{array}{l}\text { E-mail Information@Karger.de } \\
\text { www.karger.com }\end{array}$ & www.karger.com/brc
\end{tabular}

Dr. med. Toralf Reimer 
and specific histopathological types have particular prognostic or clinical characteristics [1]. The basic component of the breast is the mammary gland. Each mammary gland is made of multiple lobules connected to ducts and surrounding tissue which includes blood vessels. Malignant tumours may arise from any of the above structures. Ductal carcinomas are the most common ones (70-80\% of all cases), followed by lobular carcinomas (5-10\% of breast carcinomas) [2]. Breast tumours include a heterogeneity of rare histological subtypes (premalignant or malignant). The management of these uncommon lesions is often controversial due to the lack of large single-institution studies or randomized trials to define optimal treatments. In the era of frequent use of treatment guidelines, only a low level of evidence exists for the management of rare histological types of breast tumours. The National Comprehensive Cancer Network (NCCN) published practical guidelines for phyllodes tumour, Paget's disease, and inflammatory breast cancer [3]. The breast commission of the German gynaecological oncology guidelines provides recommendations for 'breast cancer in specific situations' including one slide regarding malignant phyllodes tumour and breast sarcomas [4]. The updated version 08.1.0 (January 2008, restricted access) presents more detailed information about rare histological types of breast neoplasms.

For better understanding, this review is divided into two parts. Firstly, the favourable histological subtypes like tubular, mucinous, medullary breast cancers, and phyllodes tumour (benign, borderline, and malignant) are discussed. The prognosis of these selected lesions is believed to be better than for invasive ductal carcinoma. Secondly, management recommendations for special situations like Paget's disease (tumour of the nipple) and inflammatory breast carcinoma are presented. This review may not cover all rare histological subtypes; the selection was made by the author with respect to frequency and clinical importance.

\section{Favourable Histological Subtypes}

\section{Tubular Carcinoma}

Pure tubular carcinomas account for less than $2 \%$ of invasive breast cancer in most series. Higher frequencies of up to $7 \%$ are found in series of small T1 breast cancers. Tubular cancers are often readily detectable mammographically because of their spiculate nature and associated cellular stroma, and are seen at higher frequencies of $9-19 \%$ in mammographic screening trials [5]. When compared with invasive carcinomas of no special type (ductal NOS), tubular carcinoma is more likely to occur in older patients, be smaller in size, and have substantially less nodal involvement [6]. Tubular carcinomas usually measure between 0.2 and $2 \mathrm{~cm}$ in diameter; the majority are $1 \mathrm{~cm}$ or less. There is a lack of consensus concerning the proportion of tubular structures required to establish the diag- nosis of tubular carcinoma. For pragmatic reasons, a $90 \%$ purity requirement for tubular structures offers a practical solution [1]. Tubular carcinoma is nearly always oestrogen and progesterone receptor-positive, well-differentiated, and mostly HER2-negative [6, 7].

Tubular carcinoma patients have an excellent prognosis. In long-term follow-up studies (> 10 years median follow-up), tubular histological type was a significant favourable factor in the uni- and multivariate survival analysis compared with invasive ductal carcinoma $[8,9]$. Ipsilateral breast tumour recurrence is rare, and localised tubular carcinomas are considered to be ideal candidates for breast conservation technique. Radiation therapy after breast conserving surgery remains standard treatment $[8,10]$. A literature review confirmed that adjuvant radiotherapy reduces local failure following breast conserving surgery for tubular carcinoma [11]. The excellent survival rate of patients with tubular cancers leads some to question the necessity of axillary staging in these patients [6, 12]. However, the incidence of axillary metastases found in patients with tubular carcinoma ranged between 4 and 17\% [6, 12-14]. The use of sentinel lymph node biopsy (SLNB) should be considered for patients with tubular carcinoma if a positive SLNB will alter adjuvant treatment [13]. Nevertheless, the survival of patients with tubular carcinoma is similar to that of the general population, and there is no proof that adjuvant therapy due to positive SLNB influences survival [6].

\section{Mucinous Carcinoma}

A variety of carcinomas of the breast are characterized by production of abundant extracellular and/or intracellular mucin. Among these are mucinous (colloid) carcinoma, mucinous cystadenocarcinoma, columnar cell mucinous carcinoma, and signet ring cell carcinoma. Mucinous carcinoma is defined by a proliferation of clusters of generally small and uniform cells floating in large amounts of extracellular mucus often visible to the naked eye [1]. Pure mucinous breast carcinoma represents $1-4 \%$ of all breast cancers and is associated with a better prognosis than infiltrative ductal carcinoma $[15,16]$. It occurs in a wide age range; the median age at diagnosis was 71 years (range 25-85) in a large retrospective review of 11,400 cases [17]. The tumour usually presents as a palpable lump. Mammographically, mucinous carcinoma appears as a well defined, lobulated lesion. On magnification or compression views, a less defined margin becomes more evident $[18,19]$. The mammographic resemblance to a benign process (circumscription and lobulation) increases with increasing mucin content. Interestingly, a delay in diagnosis, however, may not cause a significant adverse outcome for most women [20]. Traditionally, pure and mixed variants of mucinous carcinoma have been described. The 'pure' type consists of tumour tissue with extracellular mucin production with a $90 \%$ purity, while the 'mixed' form of mucinous carcinoma (50-90\% purity) also contains infiltrating 
ductal epithelial component without mucin [21]. The pure mucinous breast carcinoma cases showed a better differentiation with lesions of lesser grade and more frequent oestrogen receptor (91-94\%) and progesterone receptor (79-81\%) expression, smaller size, and less nodal involvement when compared to the infiltrating ductal carcinoma cases [17].

A large retrospective comparative analysis confirmed the less aggressive behaviour of pure mucinous carcinoma compared to infiltrating ductal carcinomas. This favourable outcome is maintained after 20 years with a 10-year breast cancer-specific survival rate of about $90 \%[16,17]$. Only $3-15 \%$ of the pure variety of mucinous carcinomas show axillary node metastases compared to $33-46 \%$ of the mixed type [1]. Axillary node involvement is a poor prognostic feature in mucinous carcinomas. Mucinous carcinomas of $\leq 1 \mathrm{~cm}$ had a $\leq 5 \%$ incidence of node involvement [6]. Analogous to tubular carcinoma, some authors suggest that axillary node dissection might not be beneficial in mucinous carcinomas measuring $\leq 1 \mathrm{~cm}[6$, 12]. However, SLNB should be considered also in these cases because positive nodal status appears to be the most significant predictor of worse prognosis $[14,17]$.

\section{Medullary Carcinoma}

Medullary carcinoma is defined as a tumour that grows in solid sheets within an indistinct cell border (syncytial growth pattern), has large vesicular nuclei and prominent nucleoli, a broad pushing margin, and a prominent lymphocytic infiltrate both at the periphery and within the tumour. These features must be present in the entire tumour for it to be regarded as a classical medullary carcinoma [22]. If the tumour has less lymphocytic infiltrate or an infiltrating margin in parts of the tumour, it is regarded as an atypical medullary carcinoma. The presence of a classical ductal carcinoma of no special type forming less than $25 \%$ of the tumour also pushes it into an atypical medullary carcinoma category. Although these features appear to be fairly specific, pathologists have a great deal of difficulty in making a diagnosis of medullary and atypical medullary carcinoma, and the interobserver agreement is low [23]. Consistent associations with both favourable (medullary or atypical medullary carcinoma) and unfavourable (high tumour grade, hormone receptor negativity, somatic p53 mutation) prognostic characteristics have been found for BRCA1-associated breast carcinomas [24]. More carcinomas were recorded as medullary or atypical medullary in the BRCA1 group (14\%) than in the control group (2\%) [25]. In general, medullary cancer is a relatively infrequent histological form of invasive breast cancer representing approximately $5 \%$ of all histological types [26].

Patients with medullary carcinoma of the breast are generally younger at the time of diagnosis than patients with infiltrating ductal carcinoma. The mean age of the women ranges from 45 to 52 years [1]. The tumour is well delineated and soft on pal- pation. Mammographically, medullary carcinoma is typically well circumscribed and may be confused with a benign lesion [27]. The tumours typically are positive for p53 and negative for oestrogen receptor and HER2 [28]. The majority of medullary carcinomas are aneuploid and highly proliferative tumours [1]. Nevertheless, medullary carcinomas showed a more favourable outcome compared with that of infiltrating ductal carcinoma [29]. It is generally agreed that patients with medullary carcinoma have a lower incidence of lymph node involvement (range 16-21\%) than normally quoted for patients with other carcinomas of the breast $[13,14]$. Axillary nodal staging and radiotherapy following breast conserving surgery are indicated in all patients with medullary carcinoma. Due to the lack of hormone receptor expression and HER2 negativity, patients with medullary carcinomas are typically no candidates for adjuvant endocrine or trastuzumab therapy. Currently, there are no clear recommendations when chemotherapy could be avoided in this favourable subtype despite its aggressive pathologic features.

\section{Phyllodes Tumour of the Breast}

Phyllodes tumours of the breast are biphasic neoplasms, basically analogous to fibroadenomas, composed of stromal and epithelial elements. Phyllodes tumours are usually benign, but recurrences are not uncommon, and a relatively small number of patients will develop haematogenous metastases. Still widespread in the literature, the generic term 'cystosarcoma phyllodes' is currently considered inappropriate and potentially dangerous since the majority of these tumours follow a benign course. It is highly preferable to use the neutral term 'phyllodes tumour', according to the view already expressed in the WHO classification of 1981 [1]. Phyllodes tumours account for less than $1 \%$ of all primary breast neoplasms. Generally, phyllodes tumour presents as a rapidly growing and clinically benign breast lump in females within the 4 th or 5 th decade of life [30]. Phyllodes tumours exist in benign (35-64\%), borderline, and malignant subtypes, although there is no uniform agreement on the criteria for assigning a subtype or for predicting biological behaviour [31]. Subtype of phyllodes tumours appears less important for risk of recurrence than does the margin of tumour-free resection achieved by surgical treatment. Diagnosis of phyllodes tumour prior to excisional biopsy/lumpectomy is uncommon [3]. Phyllodes tumours often appear on ultrasound and mammography as fibroadenomas, and core needle biopsy seems inadequate to reliably distinguish phyllodes tumour from fibroadenoma [32]. Local recurrences of phyllodes tumours are the most common site of recurrence. Positive margins, fibroproliferation in the surrounding breast tissue, and necrosis are associated with a marked increase in local recurrence rates [33]. Most distant recurrences occur in the lung, and may be solid nodules or thin-walled cavities. Patients with stromal overgrowth, particularly when the tumour 
size was $>5 \mathrm{~cm}$, were found to have a high rate of distant failure [34]. Death from phyllodes tumour is rare (2\%), and only phyllodes tumours that demonstrate uniformly aggressive pathologic features seem to be associated with mortality [33]. Wide local excision with tumour-free margins of $1 \mathrm{~cm}$ or greater is the preferred surgical therapy for patients with phyllodes tumours regardless of the histological subtype. Local excision of the tumour with negative margins results in a local control rate of approximately $90 \%$ and should be used whenever cosmetically feasible (i.e., an appropriate tumour-tobreast ratio). Total mastectomy is necessary only if negative margins cannot be obtained by breast conserving surgery [30, 34]. Since phyllodes tumours rarely metastasize to the axillary lymph nodes (10-15\%), surgical axillary staging is not necessary unless the lymph nodes are pathologic on clinical examination [35]. The role of adjuvant radiotherapy is uncertain and requires further investigation [30]. There are only few reported successful treatments with postoperative irradiation in malignant phyllodes tumours [36], its role remaining undefined because of the rarity of the condition. A prospective clinical trial, 'Phase II study of adjuvant radiotherapy after resection in patients with borderline or malignant phyllodes tumours of the breast', was initiated by the American National Cancer Institute in 1998 [37]. A total of 50 patients should have been accrued for this study within 6-7 years, however, the study is still active for recruitment. While the epithelial component of most phyllodes tumours contains oestrogen receptors $(58 \%)$ and/or progesterone receptors (75\%), endocrine therapy has no proven role in the treatment of phyllodes tumours. Similarly, there is no evidence that adjuvant cytotoxic chemotherapy provides a benefit in reducing recurrences or death $[3,4]$. In those patients who experience a local recurrence, resection of the recurrence with wide tumour-free surgical margins should be performed. Some members of the NCCN Panel recommend local radiation therapy following resection of a local recurrence, but this recommendation is controversial. The German panel discussed chemotherapy and radiotherapy as an option after R1 resection for local recurrence but gives no general recommendation for these therapies.

In summary, despite a less aggressive treatment, the survival for the described favourable histological subtypes appears to be very high, even comparable with that of women without breast cancer. After adjustment for age, stage, and grade, patients with tubular, mucinous, and medullary carcinoma, or malignant phyllodes tumours exhibited such a low risk of death that in some cases even less aggressive treatment should be considered. Patients with these specific histological types should be informed of this relatively favourable prognosis [38].

\section{Paget's Disease of the Breast}

Paget's disease of the nipple was first described in 1856 by Velpeau as an uncommon entity of the breast, followed by the description of Sir James Paget in 1874 [39], as a syndrome in which ulceration of the nipple was associated with an underlying cancer. Among patients with mammary carcinoma, Paget's disease of the breast is rare, and incidences of $0.5-5 \%$ have been reported. It occurs most commonly in postmenopausal women, with the peak incidence between the 6th and 7th decade of life at a mean age of 54 years [40]. Clinically, it is characterized by nipple or areolar erythema, eczema, ulceration, bleeding, and itching. The diagnosis of Paget's disease is often delayed for months because of its wrongful diagnosis as a benign dermatologic disease involving the nipple. The histopathological diagnosis is confirmed with a full thickness biopsy of the nipple and areola [41]. In up to $80 \%$ of cases, there is an underlying cancer elsewhere in the breast [42]. The associated cancers are not necessarily located adjacent to the nipple areolar complex (NAC), and may be either ductal carcinoma in situ (DCIS) or invasive cancer.

The most invariable association of Paget's disease of the breast with an underlying breast carcinoma has not always been reflected with imaging. In several studies, almost half of the patients had normal mammograms. The sensitivity of the mammogram in detecting malignancy seems to be significantly higher in the presence of a palpable mass (97\%), as opposed to disease confined to the nipple in the absence of a palpable mass $(50 \%)$ [40]. In patients whose disease is confined to the nipple, prognosis is better than in those accompanied by a palpable mass in the breast and suspicious mammogram [43]. In women with Paget's disease, a palpable mass or suspicious mammogram portends a high likelihood of invasive cancer. As underlying carcinoma is common even in women with a benign mammogram and no palpable mass, breast ultrasound and magnetic resonance imaging (MRI) may be useful in detecting distant lesions especially in young women [41]. The prognosis for patients with Paget's disease without palpable mass is excellent compared with that for those with an associated mass (survival: $90-100 \%$ vs. $20-60 \%$ at 5 years, and $85-100 \%$ vs. $9-60 \%$ at 10 years, respectively). The incidence of axillary lymph node involvement for Paget's disease of the breast with a palpable mass is $60 \%$. This incidence ranged from $0-15 \%$ in patients without a palpable mass [40]. Early age, tumour diameter larger than $2 \mathrm{~cm}$, and nodal involvement were consistently associated with worse prognosis [41].

Management of Paget's disease has traditionally been total mastectomy with axillary dissection. Total mastectomy remains a reasonable option for patients regardless of the absence or presence of an associated breast cancer [42]. Recent data demonstrate that satisfactory local control may be achieved with breast conserving surgery including the excision with negative margins followed by whole breast radiotherapy $[44,45]$. For Paget's disease without an associated cancer (i.e., no palpable mass or imaging abnormality), it is recommended that breast conserving surgery consists of removal of the entire NAC with a negative margin of underlying breast tissue. 
In cases with an associated cancer elsewhere in the breast, the surgery includes removal of the NAC with a negative margin, and removal of the peripheral cancer using standard breast conserving technique to achieve a negative margin. It is not necessary to remove the NAC and the peripheral cancer in continuity in a single surgical specimen or through a single incision [3]. Axillary lymph node staging is not mandatory when breast conserving therapy is used to treat Paget's disease with underlying DCIS in the absence of evidence of invasive cancer following clinical examination, imaging evaluation, and full thickness skin biopsy of the involved NAC [3]. A recently reported retrospective study has provided evidence for a high accuracy in the identification of sentinel node(s) in patients with Paget's disease [46]. Some authors consider to perform SLNB to be informed about the axillary lymph node status, and, in case of associated underlying invasive or microinvasive carcinoma, to spare the patient a second surgical approach, even if clinical and radiological exams are negative [41]. Women with Paget's disease treated with breast conservation and without an associated cancer or those with associated DCIS should consider tamoxifen for risk reduction. Those with an associated invasive cancer should receive adjuvant systemic therapy based on tumour stage and hormone receptor status [3]. In Paget's disease, the oestrogen receptor may be negative or positive, depending on the immunoprofile of the corresponding underlying carcinoma [1]. Several studies demonstrated a $88-100 \%$ HER 2 positivity for mammary Paget's disease [41, 47].

\section{Inflammatory Breast Carcinoma}

Inflammatory breast cancer (IBC) is a rare, highly aggressive form of primary epithelial breast cancer that comprises 1-6\% of breast cancer cases. It is characterized by an early age at diagnosis, poor nuclear grade, negative hormone receptor status, and poor survival outcome [48]. The American Joint Committee on Cancer (AJCC) provides the current gold standard definition for this form of breast cancer according to the 6th edition of the AJCC Cancer Staging Manual, describing it as a clinicopathologic entity that is characterized by diffuse erythema and edema (peau d'orange) over more than one third of breast surface, often without an underlying palpable mass [1]. The clinical presentation of IBC is due to tumour emboli within dermal lymphatic vessels, which may or may not be present on skin biopsy. Therefore, the AJCC relies on the clinical features of IBC and considers the pathologic features to be supportive, but not necessary for diagnosis.

In the past, IBC has often been placed under the general heading of locally advanced breast cancer. There is a growing body of evidence that IBC patients, when compared with those with non-inflammatory forms of locally advanced breast cancer, have different prognostic factor profiles and age-specific incidence rate patterns $[3,49]$. Increased angio- genesis and lymphangiogenesis have been demonstrated in IBC compared with non-IBC. Overexpression of HER2, RhoC GTPase, and NF- $\mathrm{KB}$ genes, along with loss of the gene coding for insulin-like growth factor-binding protein, have also been described in IBC [50]. The chance for distant metastases is considerably higher in IBC, and systemic staging is indicated to rule out stage IV disease. Evaluation of the extent of local disease is determined using diagnostic bilateral mammogram, with the addition of ultrasound as necessary. Sonography can be useful in diagnosing regional nodal disease. According to the NCCN guidelines, a breast MRI scan is optional, although MRI seems to be the most accurate imaging technique in detecting a primary breast parenchymal lesion in IBC patients [51, 52]. [18F]-fluorodeoxyglucose positron emission tomography (FDG PET) seems promising as an addition to current staging modalities for detection of distant metastases in IBC. However, more data are required to definitively associate this imaging modality with changes in decision making and clinical outcomes prior to the recommendation of FDG PET for use in the staging of this population of patients [50].

Multidisciplinary management of IBC, consisting of induction chemotherapy, surgery, adjuvant chemotherapy, radiotherapy, and hormonal therapy (in hormone receptor-positive disease) has improved the overall prognosis of this disease [53]. The NCCN Panel recommends preoperative chemotherapy with an anthracycline-based regimen with or without taxanes for the initial treatment of patients with IBC [3]. Inclusion of trastuzumab in the chemotherapy regimen is recommended for patients with HER2-positive disease. Patients responding to preoperative chemotherapy should undergo mastectomy with axillary lymph node dissection; breast conserving therapy is not recommended for patients with IBC [50]. Finally, postmastectomy chest wall and regional node irradiation is recommended following the completion of any planned chemotherapy. Mastectomy should not be considered for patients with IBC who do not respond to preoperative chemotherapy. Additional systemic chemotherapy and/or preoperative radiation should be an option for these patients, and patients responding to this secondary therapy should undergo mastectomy [3]. Concomitant chemoradiotherapy with cisplatin and 5-fluorouracil may be a further option for patients not responding to initial therapy [54].

Despite described combined multimodality treatment, the prognosis of IBC is poor; the 10-year disease-free survival rate is $20-25 \%$. These data clearly indicate that current treatment modalities are inadequate, and that a better understanding of the biological features of the disease is necessary if more effective interventions are to be developed [55]. Currently, the increased frequency of HER2 overexpression in IBC compared with non-IBC suggests that aberrant HER2 signalling contributes to the aggressiveness of IBC, making HER2 an attractive therapeutic target in this disease [56]. 


\section{References}

1 Tavassoli FA, Devilee P (eds): World Health Organization Classification of Tumours. Pathology and Genetics of Tumours of the Breast and Female Genital Organs. Lyon, IARC Press, 2003.

2 Liu L: Histologic classification of breast cancer. OncoLink. oncolink.upenn.edu.

3 National Comprehensive Cancer Network (NCCN): Clinical practice guidelines in oncology - version 2 , 2008. www.nccn.org.

4 Guidelines Gynäkologische Onkologie (English): Breast commission. www.ago-online.org.

$\checkmark 5$ Günhan-Bilgen I, Oktay A: Tubular carcinoma of the breast: mammographic, sonographic, clinical and pathologic findings. Eur J Radiol 2007;61:158162.

6 Diab SG, Clark GM, Osborne CK, Libby A, Allred DC, Elledge RM: Tumor characteristics and clinical outcome of tubular and mucinous breast carcinomas. J Clin Oncol 1999;17:1442-1448.

7 Oakley GJ III, Tubbs RR, Crowe J, Sebek B, Budd GT, Patrick RJ, Procop GW: HER-2 amplification in tubular carcinoma of the breast. Am J Clin Pathol 2006;126:55-58.

8 Fisher ER, Costantino JP, Leon ME, Bandos H, Palekar AS, Fisher B, Wolmark N: Pathobiology of small invasive breast cancers without metastases (T1a/b, N0, M0). NSABP Protocol B-21. Cancer 2007;110:1929-1936.

9 Vo T, Xing Y, Meric-Bernstam F, Mirza N, Vlastos G, Symmans WF, Perkins GH, Buchholz TA, Babiera GV, Kuerer HM, Bedrosian I, Akins JS, Hunt KK: Long-term outcomes in patients with mucinous, medullary, tubular, and invasive ductal carcinomas after lumpectomy. Am J Surg 2007;194: 527-531.

10 Lim M, Bellon JR, Gelman R, Silver B, Recht A Schnitt SJ, Harris JR: A prospective study of conservative surgery without radiation therapy in select patients with stage I breast cancer. Int J Radiat Oncol Biol Phys 2006;65:1149-1154.

-11 Sullivan T, Raad RA, Goldberg S, Assaad SI, Gadd M, Smith BL, Powell SN, Taghian AG: Tubular carcinoma of the breast: a retrospective analysis and review of the literature. Breast Cancer Res Treat 2005;93:199-205.

12 Maibenco DC, Weiss LK, Rawlish KS, Severson RK: Axillary lymph node metastases associated with small invasive breast carcinomas. Cancer 1999; 85:1530-1536.

13 Mendez JE, Fey JV, Cody H, Borgen PI, Sclafani LM: Can sentinel lymph node biopsy be omitted in patients with favorable breast cancer histology? Ann Surg Oncol 2005;12:24-28.

14 Wong SL, Chao C, Edwards MJ, Carlson DJ, Laidley A, Noyes RD, McGlothin T, Ley PB, Tuttle T, Schadt M, Pennington R, Legenza M, Morgan J, McMasters KM: Frequency of sentinel lymph node metastases in patients with favorable breast cancer histologic subtypes. Am J Surg 2002;184:492-498.

15 André S, Cunha F, Bernardo M, Meneses e Sousa J, Cortez F, Soares J: Mucinous carcinoma of the breast: a pathologic study of 82 cases. J Surg Oncol 1995;58:162-167.

16 Komaki K, Sakamoto G, Sugano H, Morimoto T, Monden Y: Mucinous carcinoma of the breast in Japan: a prognostic analysis based on morphologic features. Cancer 1988;61:989-996.

17 Di Saverio S, Gutierrez J, Avisar E: A retrospective review with long term follow up of 11,400 cases of pure mucinous breast carcinoma. Breast Cancer Res Treat 2007 (Epub ahead of print); DOI 10,1007/s10549-007-9809-z.
Matsuda M, Yoshimoto M, Iwase T, Takahashi K, Kasumi F, Akiyama F, Sakamoto G: Mammographic and clinicopathological features of mucinous carcinoma of the breast. Breast Cancer 2000;7: 65-70.

19 Memis A, Ozdemir N, Parildar M, Ustun EE, Erhan Y: Mucinous (colloid) breast cancer: mammographic and US features with histologic correlation. Eur J Radiol 2000;35:39-43.

20 Dhillon R, Depree P, Metcalf C, Wylie E: Screendetected mucinous breast carcinoma: potential for delayed diagnosis. Clin Radiol 2006;61:423-430.

21 Tan PH, Tse GMK, Bay BH: Mucinous breast lesions: diagnostic challenges. J Clin Pathol 2008;61: 11-19.

22 Ridolfi RL, Rosen PP, Port A, Kinne D, Mike V: Medullary carcinoma of the breast: a clinicopathologic study with 10 year follow up. Cancer 1977;40: 1365-1385.

23 Lakhani SR: The pathology of familial breast cancer: morphological aspects. Breast Cancer Res 1999;1:31-35.

24 Phillips KA, Andrulis IL, Goodwin PJ: Breast carcinomas arising in carriers of mutations in BRCA1 or BRCA2: are they prognostically different? J Clin Oncol 1999;17:3653-3663.

25 Marcus JN, Watson P, Page DL, Narod SA, Lenoir GM, Tonin P, Linder-Stephenson L, Salerno G, Conway TA, Lynch HT: Hereditary breast cancer: pathobiology, prognosis, and BRCA1 and BRCA2 gene linkage. Cancer 1996;77:697-709.

26 Fisher ER, Kenny JP, Sass R, Dimitrov NV, Siderits RH, Fisher B: Medullary cancer of the breast revisited. Breast Cancer Res Treat 1990;16:215-229.

27 Majid AS, Shaw de Paredes E, Doherty RD, Sharma NR, Salvador X: Missed breast carcinoma: pitfalls and pearls. RadioGraphics 2003;23:881-895.

28 Eichhorn JH: Medullary carcinoma, provocative now as then. Semin Diagn Pathol 2004;21:65-73.

29 Pedersen L, Holck S, Schiodt T: Medullary carcinoma of the breast. Cancer Treat Rev 1988;15: 53-63.

30 Macdonald OK, Lee CM, Tward JD, Chappel CG, Gaffney DK: Malignant phyllodes tumor of the female breast. Cancer 2006;107:2127-2133.

31 Anderson BO, Lawton TJ, Lehman CD, Moe RE: Phyllodes tumors; in Harris JR, Lippman ME, Morrow M, Osborne CK (eds): Diseases of the breast. Philadelphia, Lippincott Williams and Wilkins, 2004.

32 Salvadori B, Cusumano F, Del Bo R, Delledonne V, Grassi M, Rovini D, Saccozzi R, Andreola S, Clemente C: Surgical treatment of phyllodes tumors of the breast. Cancer 1989;63:2532-2536.

33 Barrio AV, Clark BD, Goldberg JI, Hoque LW, Bernik SF, Flynn LW, Susnik B, Giri D, Polo K, Patil S, Van Zee KJ: Clinicopathologic features and long-term outcomes of 293 phyllodes tumors of the breast. Ann Surg Oncol 2007;14:2961-2970.

34 Chaney AW, Pollack A, Mcneese MD, Zagars GK, Pisters PWT, Pollock RE, Hunt KK: Primary treatment of cystosarcoma phyllodes of the breast. Cancer 2000;89:1502-1511.

35 Magi AA, Smith BL, Gadd MA, Tanabe KK, Ott MJ, Souba WW: Surgical management of phyllodes tumors. Arch Surg 1999;134:487-492.

36 Soumarová R, Seneklová Z, Horová H, Vojkovská H, Horová I, Budiková M, Ruzicková J, Jezková B: Retrospective analysis of 25 women with malignant cystosarcoma phyllodes- treatment results. Arch Gynecol Obstet 2004;269:278-281.
Kraemer B, Hoffmann J, Roehm C, Gall C, Wallwiener D, Krainick-Strobel U: Cystosarcoma phyllodes of the breast: a rare diagnosis: case studies and review of literature. Arch Gynecol Obstet 2007;276:649-653.

38 Louwman MW, Vriezen M, van Beek MW, Nolthenius-Puylaert MC, van der Sangen MJ, Roumen RM, Kiemeney LA, Coebergh JW: Uncommon breast tumors in perspective: incidence, treatment and survival in the Netherlands. Int J Cancer 2007;121:127-135.

39 Paget J: On disease of the mammary areola preceding carcinoma of the mammary gland. St Bartholomews Hosp Rep 1874;10:87-89.

40 Sakorafas GH, Blanchard K, Sarr MG, Farley DR Paget's disease of the breast. Cancer Treat Rev 2001;27:9-18

41 Caliskan M, Gatti G, Sosnovskikh I, Rotmensz N, Botteri E, Musmeci S, Rosali dos Santos G, Viale G, Luini A: Paget's disease of the breast: the experience of the European institute of oncology and review of the literature. Breast Cancer Res Treat 2008 (Epub ahead of print); DOI: 10.1007/s10549_ 007-9880-5.

42 Marcus E: The management of Paget's disease of the breast. Curr Treat Options Oncol 2004;5:153-160.

43 Zakaria S, Pantvaidya G, Ghosh K, Degnim AC: Paget's disease of the breast: accuracy of preoperative assessment. Breast Cancer Res Treat 2007;102:137-142.

44 Dalberg K, Hellborg H, Wärnberg F: Paget's disease of the nipple in a population based cohort. Breast Cancer Res Treat 2007 (Epub ahead of print); DOI: 10.1007/s10549-007-9783-5.

45 Kawase K, Dimaio DJ, Tucker SL, Buchholz TA, Ross MI, Feig BW, Kuerer HM, Meric-Bernstam F, Babiera G, Ames FC, Singletary SE, Hunt KK Paget's disease of the breast: there is a role of breast-conserving therapy. Ann Surg Oncol 2005; 12:391-397.

46 Sukumvanich P, Bentrem DJ, Cody HS 3rd, Brogi E, Fey JV, Borgen PI, Gemignani ML: The role of sentinel lymph node biopsy in Paget's disease of the breast. Ann Surg Oncol 2007;14:1020-1023.

47 Horn LC, Purz S, Krumpe C, Bilek K: COX2 and Her-2/neu are overexpressed in Paget's disease of the vulva and the breast: results of a preliminary study. Arch Gynecol Obstet 2008;277:135-138.

48 Hance KW, Anderson WF, Devesa SS, Young HA Levine PH: Trends in inflammatory breast carcinoma incidence and survival: the Surveillance, Epidemiology, and End Results Program at the National Cancer Institute. J Natl Cancer Inst 2005;97: 966-975.

49 Anderson WF, Chu KC, Chang S: Inflammatory breast carcinoma and noninflammatory locally advanced breast carcinoma: distinct clinicopathologic entities? J Clin Oncol 2003;21:2254-2259.

50 Chia S, Swain SM, Byrd DR, Mankoff DA: Locally advanced and inflammatory breast cancer. J Clin Oncol 2008;26:786-790.

51 Renz DM, Baltzer PA, Böttcher J, Thaher F, Gajda M, Camara O, Runnebaum IB, Kaiser WA: Inflammatory breast carcinoma in magnetic resonance imaging a comparison with locally advanced breast cancer. Acad Radiol 2008, 15:209-221.

52 Yang WT, Le Petross HT, Macapinlac H, Carkaci S, Gonzalez-Angulo AM, Dawood S, Resetkova E, Hortobagyi GN, Cristofanilli M: Inflammatory breast cancer: PET/CT, MRI, mammography, and sonography findings. Breast Cancer Res Treat DOI: 10.1007/s10549-007-9671-Z. 
53 Cristofanilli M, Valero V, Buzdar AU, Kau SW, Broglio KR, Gonzalez-Angulo AM, Sneige N, Islam R, Ueno NT, Buchholz TA, Singletary SE, Hortobagyi GN: Inflammatory breast cancer (IBC) and patterns of recurrence: understanding the biology of a unique disease. Cancer 2007;110:1436-1444.

54 Genet D, Lejeune C, Bonnier P, Aubard Y, VenatBouvet L, Adjadj DJ, Martin J, Labourey JL, Benyoub A, Clavere P, Lebrun-Ly V, Juin P, Piana L, Tubiana-Mathieu N: Concomitant intensive chemoradiotherapy induction in non-metastatic inflammatory breast cancer: long term follow-up. $\mathrm{Br} \mathrm{J}$ Cancer 2007;97:883-887.
Cabioglu N, Gong Y, Islam R, Broglio KR, Sneige N, Sahin A, Gonzalez-Angulo AM, Morandi P, Bucana C, Hortobagyi GN, Cristofanilli M: Expression of growth factor and chemokine receptors: new insights in the biology of inflammatory breast cancer. Ann Oncol 2007;18:1021-1029.
56 Johnston S, Trudeau M, Kaufman B, Boussen H, Blackwell K, LoRusso P, Lombardi DP, Ben Ahmed S, Citrin DL, DeSilvio ML, Harris J, Westlund RE, Salazar V, Zaks TZ, Spector NL: Phase II study of predictive biomarker profiles for response targeting human epidermal growth factor receptor 2 (HER-2) in advanced inflammatory breast cancer with lapatinib monotherapy. J Clin Oncol 2008;26:1066-1072. 